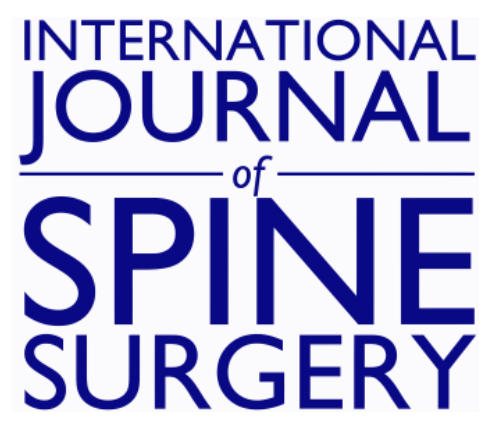

\title{
Floating Vertebral Body Cement Ball After High-Viscosity-Cement Vertebroplasty for Lytic Defect: Report of 2 Cases
}

TARUSH RUSTAGI, ERIC BOUREKAS and EHUD MENDEL

Int J Spine Surg 2020, 14 (4) 594-598

doi: https://doi.org/10.14444/7079

http://ijssurgery.com/content/14/4/594

This information is current as of April 25, 2023.

Email Alerts Receive free email-alerts when new articles cite this article. Sign up at:

http://ijssurgery.com/alerts

The International Journal of Spine Surgery

2397 Waterbury Circle, Suite 1,

Aurora, IL 60504, Phone: +1-630-375-1432 


\title{
Floating Vertebral Body Cement Ball After High-Viscosity- Cement Vertebroplasty for Lytic Defect: Report of 2 Cases
}

\author{
TARUSH RUSTAGI, MD, ${ }^{1,2}$ ERIC BOUREKAS, MD, MBA, ${ }^{1}$ EHUD MENDEL, MD, MBA ${ }^{1}$ \\ ${ }^{I}$ Ohio State University Wexner Medical Center and Arthur G. James Cancer Hospital, Columbus, Ohio, ${ }^{2}$ Indian Spinal Injuries Centre, New Delhi, India
}

\begin{abstract}
Background: Percutaneous vertebroplasty (PVP) is an effective procedure for painful pathological vertebral fractures. High-viscosity cement is the preferred choice for vertebroplasty given its low risk of extravasation. We describe here 2 cases of high-viscosity cement vertebroplasty in large lytic defects and associated complications.

Case Description: Case 1 describes PVP in an 89-year-old male patient with L1 pathological fracture from prostrate metastasis. Case 2 describes PVP in a 68-year-old male with T7 and T8 vertebral fractures from multiple myeloma. In both cases, high-viscosity cement was used to fill large lytic cavities. This resulted in poor interdigitation of the cement with the trabeculae forming an unstable floating cement ball and dangerous retrieval of the cement trocar needle. The implications of this occurrence have been described.

Conclusions: High-viscosity-cement vertebroplasty in large lytic defects needs to be done with caution. The potential occurrence of poor cement interdigitation and the following complications can be catastrophic, and caution must be used.
\end{abstract}

Complications

Keywords: vertebroplasty, complications, PMMA, pathological fracture

\section{INTRODUCTION}

Percutaneous vertebroplasty (PVP) is an effective procedure for pain alleviation following vertebral fractures from osteoporosis or metastasis. ${ }^{1,2}$ Cement augmentation has been found to decrease pain by up to $90 \%$ within 24 hours. ${ }^{3}$ The procedure, although less invasive and widely acceptable, carries significant risk of complications, especially related to cement leaks. ${ }^{4}$ Injection techniques, fracture characteristics, and the physical properties of the cement largely influence the incidence of cement leakage. ${ }^{5}$ Currently, high-viscosity cement (HVC) is preferred for its significantly low incidence of leakage. ${ }^{5}$ We describe here 2 cases of HVC vertebroplasty resulting in a floating vertebral body cement ball as a complication and discuss its implications and prevention strategies.

\section{CASE REPORT}

The procedure was performed under general anesthesia in the prone position; PVP was performed according to the method described by O'Brien et al. ${ }^{6}$ In both the cases, HVC was used (Confidence, DePuy Spine, Raynham, Massachu- setts). Briefly, a small stab incision was made on the skin. An 11-ga (12-cm) trocar was placed from an oblique position under fluoroscopy with an attempt to place the tip of the needle just across the midline in the antero-posterior view and in the anterior aspect of the vertebral body in the lateral view. After confirming the placement of the needle, the cement was injected slowly under live continuous fluoroscopy to allow gradual filling of the vertebral body by cement. The working time of the cement is known to be $8-10$ minutes following the mixing of the components, during which time it allows for a stable viscosity for injection. ${ }^{4}$ The cement then rapidly hardens. The end point was determined as adequate filling, evidence of cement extravasation, or excessive pressure encountered during injection.

\section{Case 1}

An 89-year-old male with a known history of metastatic prostate cancer presented with worsening back pain of 1-month duration. The pain was mechanical (worsening with change of position and activity) and rated as $10 / 10$ on the visual analog scale (VAS) during ambulation. The neurological examination was normal. Computed tomography (CT) 


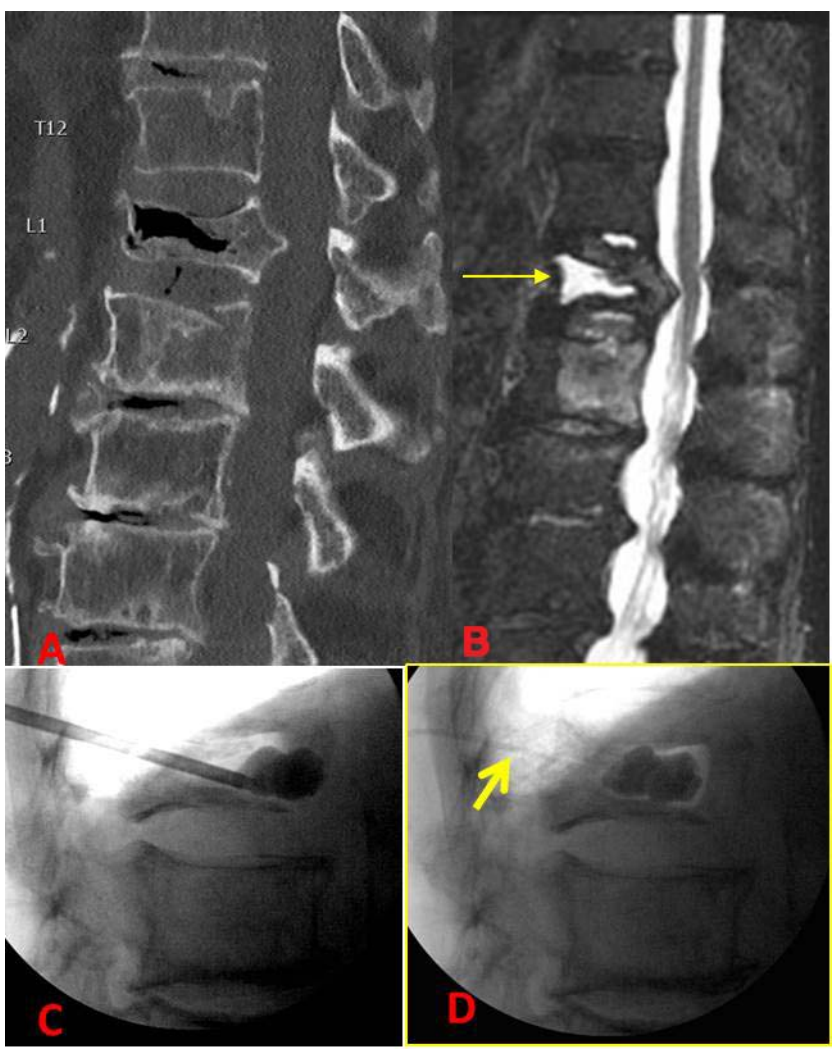

Figure 1. (A) Computed tomography (CT) sagittal image showing the cleft in the L1 vertebrae. (B) Magnetic resonance imaging (MRI) showing fluid-filled lytic cleft (thin yellow arrow). (C) Cement mass stuck to the trocar. (D) Thick Yellow arrow showing the cement tail. The cement mass moved dorsally with removal of the trocar.

scan images showed a severe fracture involving the L1 vertebra with a cleft and mild retropulsion of bone into the spinal canal (Figure 1A). Magnetic resonance imaging ( $\mathrm{T} 1 \mathrm{~W}$ postcontrast images) suggested metastatic involvement of the vertebra with a large fluid-filled cleft (Figure 1B). Following discussion of the procedure, a PVP was performed using a left-sided, transpedicular approach. After about 11 minutes following the mixing of the cement, the injection was stopped. The stylet of the needle could not be introduced back into the cannula due to cement within the cannula. We attempted to remove the cannula, but there was resistance. The trocar was then turned to disengage from the cement in preparation to be pulled out. At this time, the cannula of the needle was found stuck to the cement ball, which itself was moving freely within the cleft (Figure 1C, D). Under fluoroscopy control, another attempted rotation of the needle freed it from the cement ball. As the trocar was pulled out, a hardened tail of cement was left behind, emerging through the incision (Figure 1D). The cement tail was attached to the cement ball and was cut as deep as possible. Immediate postoperative $\mathrm{CT}$ scan showed that the cement did not interdigitate with the trabeculae and was lying in the cleft, connected through a long tail (Figure 2). Clinically, the patient had marked pain relief in the immediate postoperative period. A repeat CT scan after 3 days showed that the cement ball had moved (Figure 2B). The patient declined any further intervention. At 3 weeks follow-up, following an initial improvement in pain, the pain had again become severe to the extent that it was impeding his ambulation. Repeat x-rays and CT scan at this stage showed further collapse. The cement tail had fractured, and the cement mass had turned horizontally (Figure 2C). Flexion-extension x-rays showed significant intravertebral instability (Figure 3A, B). Following a detailed discussion with the patient, a posterior fusion surgery was done from T10 to L4 (Figure 3C). Afterward, the patient had good pain relief and was able to ambulate well.

\section{Case 2}

A 68-year-old male with multiple myeloma and multiple spine metastasis presented with mechanical pain in the mid-thoracic region (VAS score 8). CT scan and x-ray images showed compression fractures of $\mathrm{T} 7$ and $\mathrm{T} 8$ with a large lytic defect involving the

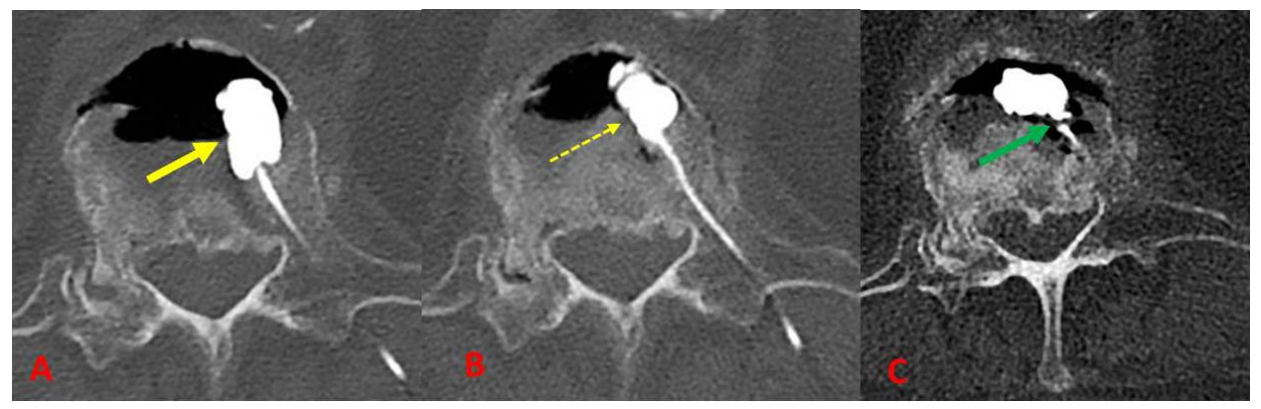

Figure 2. (A) Computed tomography (CT) scan axial images showing cement mass lying in the lytic cleft (bold yellow arrow). (B) CT scan axial images after $3 \mathrm{~d}$ showing ventral movement of the cement (dashed yellow arrow). (C) CT scan sagittal and axial images before surgery showing further rotation of the cement mass and fracture of the tail (green arrow). 


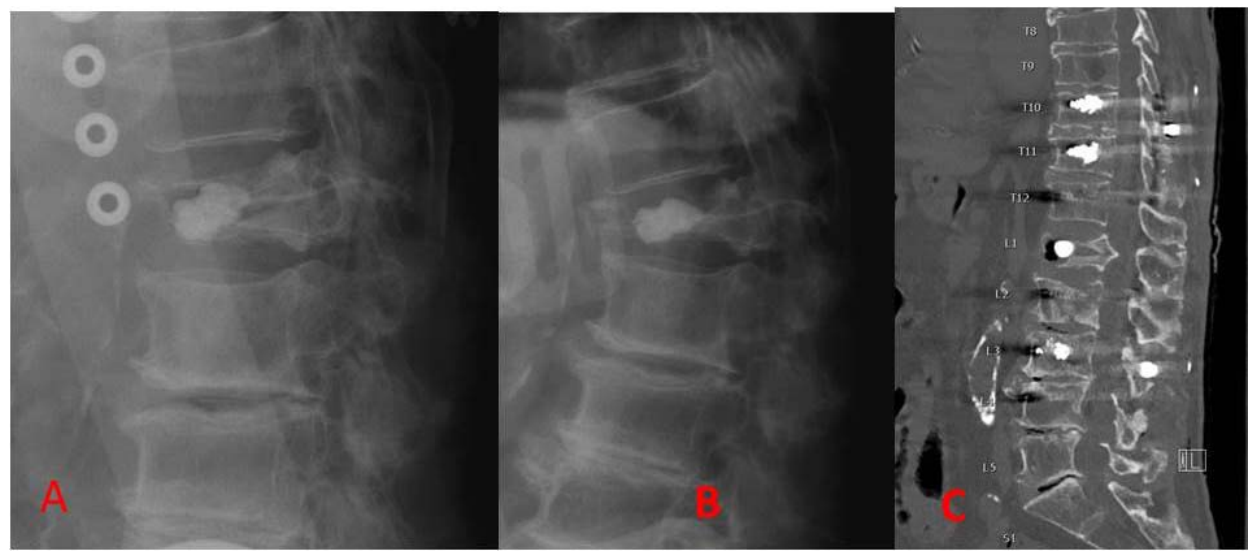

Figure 3. (A, B) Flexion and extension $x$-rays in brace showing significant intravertebral instability. (C) Sagittal computed tomography scan image showing posterior fixation with cement-augmented pedicle screws.

T8 vertebra (Figure 4A, B). The patient was scheduled for a bone marrow transplant (BMT) that precluded him from undergoing any open surgical intervention. Following BMT, he could not have had any surgical procedure for a period of 3 months. This scenario left us to either closely observe him, where he could have fractured further and deteriorated neurologically or, consider PVP. Following detailed discussion, HVC vertebroplasty was performed at both levels using transpedicular, unilateral approaches at both levels. At the T8 level, after around 10 minutes of injection, an initial attempt to withdraw the trocar was unsuccessful. The trocar was noted to be stuck to the cement. The cement mass itself was not interdigitated with the trabeculae and was turning freely with the rotation of the trocar (Figure

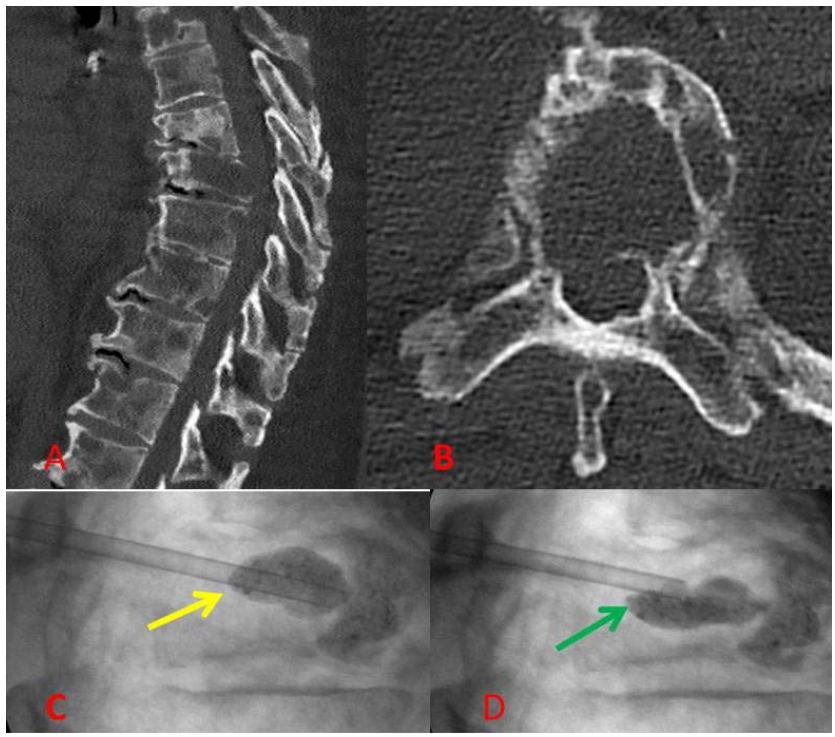

Figure 4. (A, B) Sagittal and axial computed tomography images showing large lytic defects involving the T8 vertebra. (C, D) Intraoperative image showing rotation of the cement mass with the trocar (yellow and green arrows).
$4 \mathrm{C}, \mathrm{D})$. After repeated forced twisting, the trocar was detached. The cement ball itself had rotated by this time. The patient had significant pain relief from the procedure. Subsequent X-rays and CT scan showed stable cement position; it was discussed whether to keep a close eye on it (Figure 5). The patient eventually underwent BMT and is doing well.

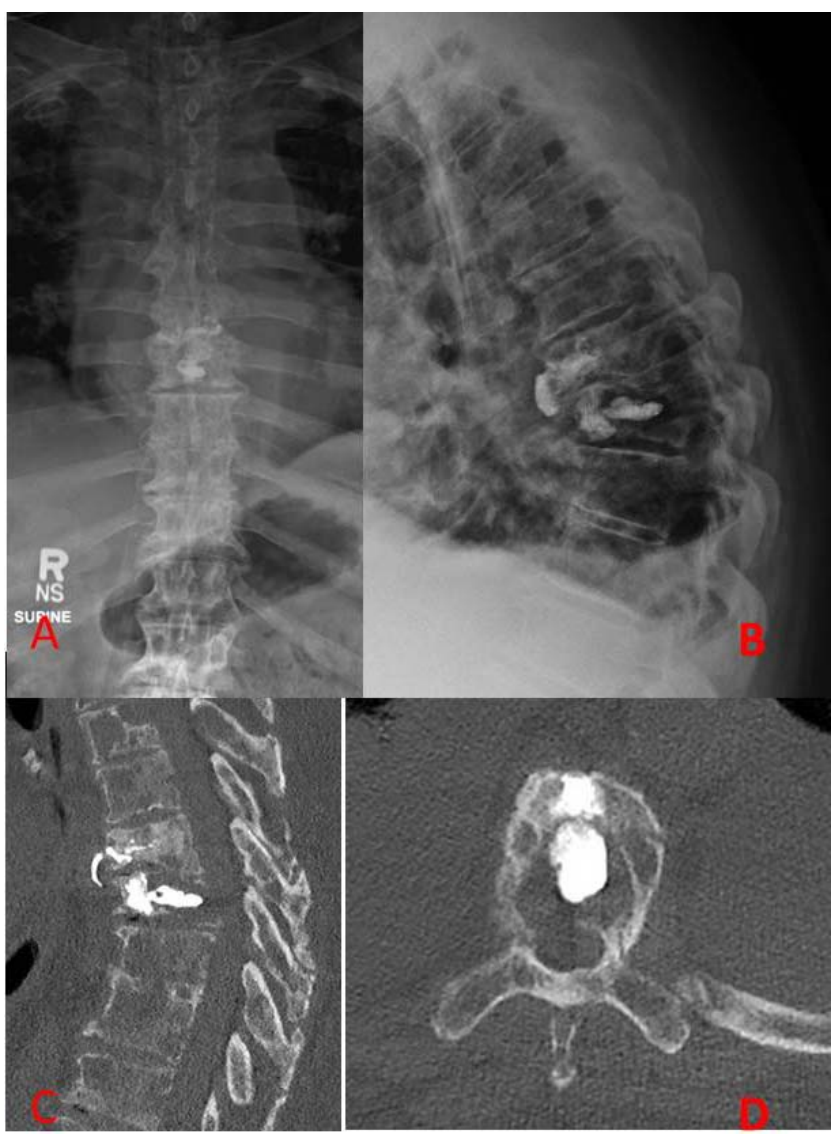

Figure 5. (A, B) Standing antero-posterior and lateral x-rays showing T7-T8 vertebroplasty. (C, D) Sagittal and axial image showing cement in the lytic T8 vertebral body. 


\section{DISCUSSION}

Here we describe 2 cases of floating cement masses following use of high-viscosity PVP in severe vertebral fractures with lytic defects and/or clefts/ cavities.

Pathological vertebral compression fractures follow bone weakening from osteoporosis or other processes, including metastasis. Surgical options are often constrained by age, morbidity, poor bone quality, and poor cancer survival. ${ }^{7,8}$ PVP has been accepted as a standard minimally invasive treatment option of pathological vertebral fractures allowing for rapid improvement of pain relief and improving the quality of life. ${ }^{9-11}$ These fractures are often severe and associated with cortical breach and lytic defects, potentially carrying high risk of cement leakage. In a recent meta-analysis, Zhan et $\mathrm{al}^{5}$ found vertebral clefts, low-viscosity cement, cortical disruption, and high volume of injection to be significant risk factors for cement leakage. Incidence of cement leakage has been reported to be between $78 \%$ and $91.9 \%$ with low-viscosity cement. ${ }^{12-14}$ The clinical significance from leakage, however, is not high considering that only a small proportion of these leaks are symptomatic $(3.9 \%-7.54 \%){ }^{4}$

Low-viscosity cement is typically injected 4-8 minutes after the components are mixed and then undergoes a gradual hardening process. HVC, on the other hand, can be injected less than a minute after the components are mixed. ${ }^{4}$ HVC offers the advantage of allowing 8-10 minutes of stable viscosity for injecting and is preferred over LVC for PVP. ${ }^{4,5}$ HVC offers the advantage of having a lower risk of extravasation and allows for a more uniform cement filling pattern. ${ }^{2,4,5}$ Georgy $^{15}$ found that the extravasation rate of $\mathrm{HVC}$ is comparable to kyphoplasty. The cement needs to be injected continuously to allow for a homogeneous mass. Any inhomogeneity leads to increased stress on the cement and reduces the life span. ${ }^{16}$ Due to the lower rate of leakage, $\mathrm{HVC}$ is preferred by many over LVC. However, one must be cognizant of the rising pressure while injecting HVC. High pressure may be associated with increased incidence of fat embolism or bone marrow entering the circulation. ${ }^{14,16,17}$ Forceful injection has been found to cause monomers to separate from cement suspension. ${ }^{14}$ Baroud et $\mathrm{al}^{16}$ suggested that the use of HVC may cause the weak trabeculae to break as it is pushed against the hard cement instead of interdigitating.
We feel that while HVC is a useful and a safe option, it needs to be injected with care in large clefts or lytic defects. Since HVC expands to form a gradually enlarging ball of cement, in a large cleft, it may not have enough time and fluidity to interdigitate with the sparse trabeculae before hardening. This was seen in both our cases where the cement failed to interdigitate. This led to a floating mass of cement in a large lytic cavity. In both the cases, since the cement was free, the trocar itself could not be readily freed from the cement ball. This was an interesting observation, as we were worried about how to safely free the trocar from the cement mass. While we were lucky that the trocar eventually freed up with slow toand-fro rotatory movements, in a worst-case scenario, attempts to free the trocar could be dangerous. The cement itself could be pulled back toward the spinal canal, possibly causing spinal cord injury, particularly in the setting of an absent posterior wall, or the floating cement could have potentially induced further fracture of the trabeculae. ${ }^{16}$ An open surgery may have to be performed to disengage the trocar in failed cases. The authors feel that in the presence of a large cleft, as was seen in both our cases, injecting HVC requires a different approach. First, the cement likely needs to be injected at a faster-than-usual rate in order to allow the cement to enlarge quickly enough to interdigitate with the trabeculae. Second, the trocar may need to be turned every few minutes in order to make sure it does not adhere to the cement. The authors also strongly suggest that the trocar, if stuck to the cement ball, needs to be disengaged using rotatory movements and not by blindly pulling it. It is critical to perform this action rapidly before the cement sets too hard to disengage the trocar. Zhang et $\mathrm{al}^{4}$ also suggested that the trocar, in cases where HVC is used, should be withdrawn quickly since the cement does not leak from the trocar due to its higher viscosity. In contrast, for LVC, the trocar is left for a longer period of time to prevent any leakage until polymerization is complete. ${ }^{4}$ Fluoroscopy should be used thoroughly; this is important not only to be able to see the dorsal translation of the body cement with the trocar but also to assess for tailing of the cement (as seen in our case 1). The tail may act like a tether and pull the body cement dorsally while retrieving the trocar. The viscosity of the cement may cause the cement to harden inside the cannula of the trocar itself if not removed quickly, as we saw in our case.

Adjusting cement viscosity and determining the right fluidity require further research. Most sur- 
geons and interventionists rely on experience to judge the viscosity based on how the cement flows through the needle before injecting. ${ }^{18}$ Perhaps it would be ideal to have a mid-viscosity or a variableviscosity cement available for injecting in large lytic defects. ${ }^{16}$ Additionally, surgeons may consider discussing formal fusion surgery earlier if they feel that the cement has interdigitated adequately.

The 2 cases presented here highlight potential issues related to injecting $\mathrm{HVC}$ in large lytic defects and clefts that have not been previously reported. This will make surgeons and interventionists aware of possible solutions to avoid and manage this potential complication.

\section{CONCLUSIONS}

We report 2 cases of floating cement mass following $\mathrm{HVC}$, presenting as a floating vertebral body cement ball. We discuss the factors associated and preventive strategies.

\section{ACKNOWLEDGMENTS}

The authors wish to thank Reghan Borer and the Neuroscience Research Institute at Ohio State University for editing support.

\section{REFERENCES}

1. Heini PF, Walchli B, Berlemann U. Percutaneous transpedicular vertebroplasty with PMMA: operative technique and early results. A prospective study for the treatment of osteoporotic compression fractures. Eur Spine J. 2000;9(5):445-450.

2. Fourney DR, Schomer DF, Nader R, et al. Percutaneous vertebroplasty and kyphoplasty for painful vertebral body fractures in cancer patients. J Neurosurg Spine. 2003;98(1):21-30.

3. Kaemmerlen $\mathrm{P}$, Thiesse $\mathrm{P}$, Jonas $\mathrm{P}$, et al. Percutaneous injection of orthopedic cement in metastatic vertebral lesions. New Engl J Med. 1989;321(2):121-126.

4. Zhang L, Wang J, Feng X, et al. A comparison of high viscosity bone cement and low viscosity bone cement vertebroplasty for severe osteoporotic vertebral compression fractures. Clin Neurol Neurosurg. 2015;129:10-16.

5. Zhan Y, Jiang J, Liao H, Tan H, Yang K. Risk factors for cement leakage after vertebroplasty or kyphoplasty: a metaanalysis of published evidence. World Neurosurg.2017;101:633642.

6. O’Brien JP, Sims JT, Evans AJ. Vertebroplasty in patients with severe vertebral compression fractures: a technical report. Am J Neuroradiol. 2000;21(8):1555-1558.

7. Patil S, Rawall S, Singh D, et al. Surgical patterns in osteoporotic vertebral compression fractures. Eur Spine J. 2013;22(4):883-891.
8. Shen WJ, Liu TJ, Shen YS. Nonoperative treatment versus posterior fixation for thoracolumbar junction burst fractures without neurologic deficit. Spine (Phila Pa 1976). 2001;26(9):1038-1045.

9. Chen D, An ZQ, Song S, Tang JF, Qin H. Percutaneous vertebroplasty compared with conservative treatment in patients with chronic painful osteoporotic spinal fractures. J Clin Neurosci. 2014;21(3):473-477.

10. Xiaochun Li M, Min Yao M, Penfei Y, Xiang Qian M. Comparing pain reduction following vertebroplasty and conservative treatment for osteoporotic vertebral compression fractures: a meta-analysis of randomized controlled trials. Pain Phys. 2013;16:455-464.

11. Lange A, Kasperk C, Alvares L, Sauermann S, Braun S. Survival and cost comparison of kyphoplasty and percutaneous vertebroplasty using German claims data. Spine. 2014;39(4):318-326.

12. Peh WC, Gilula LA, Peck DD. Percutaneous vertebroplasty for severe osteoporotic vertebral body compression fractures. Radiology. 2002;223(1):121-126.

13. Chen C, Bian J, Zhang W, Zhang W, Zhao C, Wei H. Unilateral versus bilateral vertebroplasty for severe osteoporotic vertebral compression fractures. Clin Spine Surg. 2014;27(8):E301-E104.

14. Young C, Munk PL, Heran MK, et al. Treatment of severe vertebral body compression fractures with percutaneous vertebroplasty. Skeletal Radiol. 2011;40(12):1531-1536.

15. Georgy BA. Clinical experience with high-viscosity cements for percutaneous vertebral body augmentation: occurrence, degree, and location of cement leakage compared with kyphoplasty. Am J Neuroradiol. 2010;31(3):504-508.

16. Baroud G, Crookshank M, Bohner M. High-viscosity cement significantly enhances uniformity of cement filling in vertebroplasty: an experimental model and study on cement leakage. Spine. 2006;31(22):2562-2568.

17. Aebli N, Krebs J, Davis G, Walton M, Williams MJ, Theis JC. Fat embolism and acute hypotension during vertebroplasty: an experimental study in sheep. Spine. 2002;27(5):460-466.

18. Heini PF, Berlemann U, Kauffman M, et al. Augmentation of mechanical properties in osteoporotic vertebral bodies - a biomechanical investigation of vertebroplasty efficacy with different bone cements. Eur Spine J. 2001;10(2):164-171.

Corresponding Author: Tarush Rustagi, MD, Department of Neurosurgery, Ohio State University, $410 \mathrm{~W}, 10^{\text {th }}$ Avenue, Columbus, $\mathrm{OH}$ 43210. Phone: (747) 275-2226; Email: tarush. rustagi@gmail.com.

Published 28 August 2020

This manuscript is generously published free of charge by ISASS, the International Society for the Advancement of Spine Surgery. Copyright $\odot 2020$ ISASS. To see more or order reprints or permissions, see http://ijssurgery.com. 